Copyright (C) 2014 by Academic Publishing House Researcher

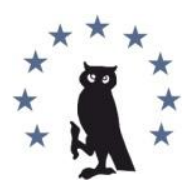

Published in the Russian Federation

European Researcher

Has been issued since 2010.

ISSN 2219-8229

E-ISSN 2224-0136

Vol. 85, No. 10-2, pp. 1828-1834, 2014

DOI: $10.13187 / \mathrm{er} .2014 .85 .1828$

www.erjournal.ru

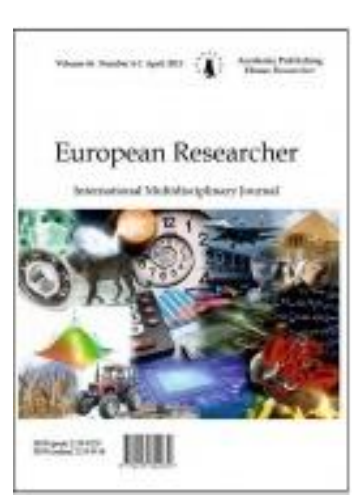

UDC 04.514.62:681.5: 676.026.1

\title{
Software and Hardware Complex of Experimental Plant for Pulp and Paper Production
}

\author{
${ }^{1}$ Anton A. Kaverin \\ ${ }^{2}$ Dmitry A. Dadenkov
}

\author{
${ }^{1}$ Perm National Research Polytechnic University, Russian Federation \\ 29, Komsomolsky Ave., 614990, Perm \\ Graduate student \\ E-mail: kaa@mail.msa.pstu.ru \\ 2 Perm National Research Polytechnic University, Russian Federation \\ 29, Komsomolsky Ave., 614990, Perm \\ Lecturer \\ E-mail: dadenkov@mail.ru
}

\section{Abstract}

This paper describes the process of developing the software and hardware complex in the programming environment LabVIEW for study and identification of plant operation modes that simulates the real manufacturing process of preparing paper pulp. The specific feature of the developed software complex is its connection with the technological process of the experimental plant by a programming logic controller.

Keywords: Physical model; experimental plant; programming logic controller; block diagram; front panel.

\section{Introduction}

The technological cycle of paper production is distinguished by large branching and a great number of inter-related parameters [1]. The quality of the products depends on each parameter. Since it is not appropriate to conduct experiments by means of existing equipment, the investigation of the technological operation modes of production processes, with the construction of physical models has been proposed [2].

The object of software and hardware complex construction is the development of a physical model and building the laboratory plant on its basis.

The developed experimental plant simulates the operation of the local loop control of the pulp preparing process in pulp and paper production.

The laboratory plant consists of five tanks, connected to the piping system in sequence. The tanks simulate the technological pools of real technological section for pulp preparation. The piping system contains four pumps with frequency controlled electric drive, manual and controlled valves with an electric drive, tubular heater, sensors of the main technological 
parameters - flow, pressure, concentration. All the tanks are equipped with level sensors, overflow protection system and are connected to a drainage system of mass draining through manual valves [3].

\section{Materials and Methods}

To provide experimental works in a laboratory plant the software and hardware complex is required that would allow the researchers to implement different modes and functions to control the plant, and also would ensure the reception and investigation of various static and dynamic characteristics. The designed software and hardware complex at its early stage of development will perform the simple functions of mode control of the plant operation and ensure the acquisition, storage and processing the experimental data.

In order to construct the educational and experimental complex of technological process control of the experimental plant a software package application from National Instruments LabVIEW has been proposed [4].

The package LabVIEW is based on graphical programming environment, which is now widespread among experts and researchers in this area. It enables the users to implement engineering and scientific development in the systems of measurement, testing, controlling and automation of scientific experiments [5].

By development of software complex for experimental plant control and data acquisition it is necessary to create a user-friendly, visual interface. Package-based tools make it possible to implement data mapping and program control. Thus, the necessity of third-party packages usage for data visualization is eliminated that allows users to perform acquisition, analysis, processing and display of data in a single application without the problems of format compatibility. In addition, LabVIEW can be turned into a full SCADA-system with an optional module Datalogging \& Supervisory Control Module (DSC), designed for graphical development applications of monitoring and control [6].

Block diagram of software and hardware complex of the experimental plant is shown in Figure 1.

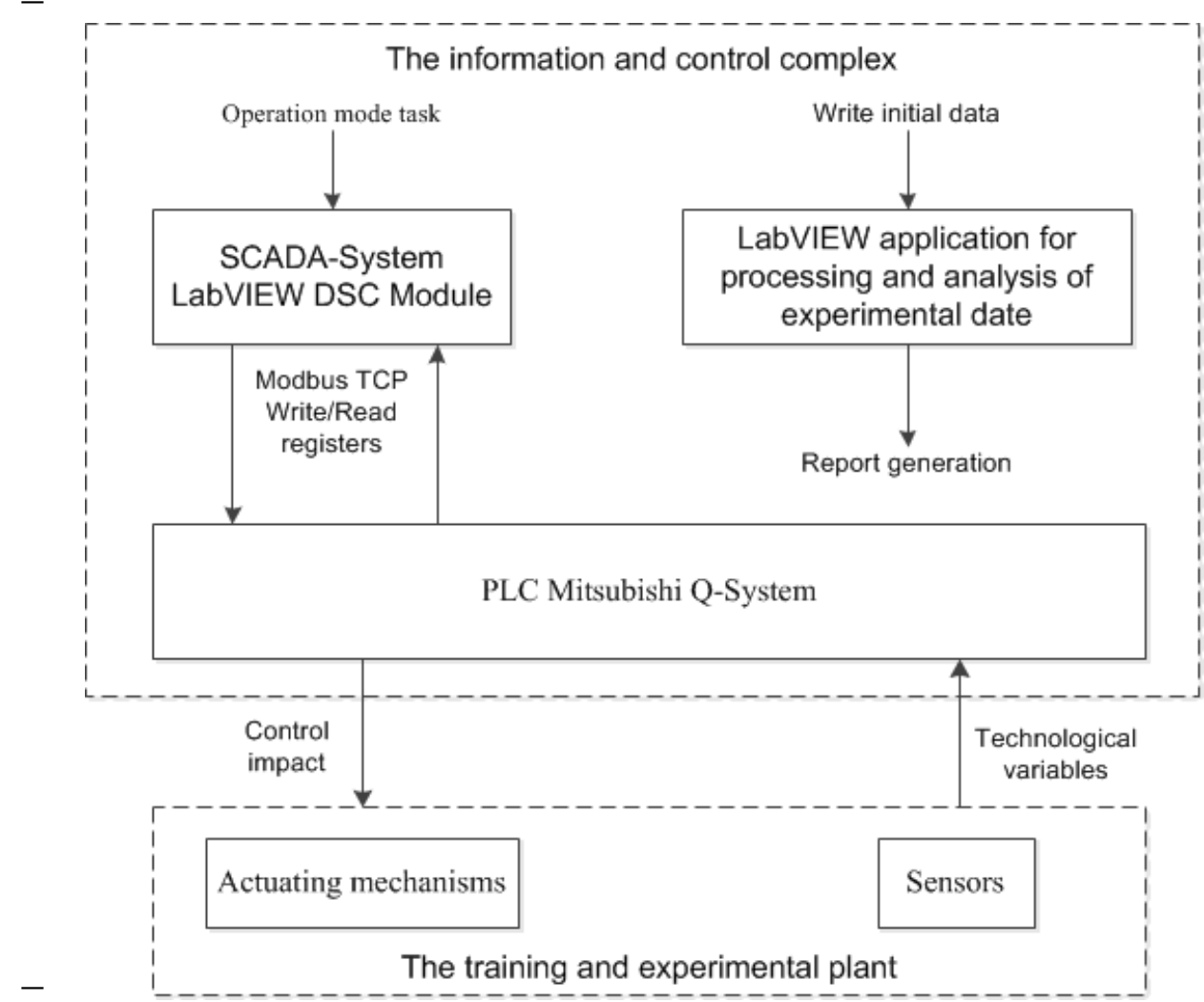

Fig. 1. Block diagram of software and hardware complex 
The software and hardware complex consists of two control levels. In the middle level there is a programmable logic controller (PLC) Q-System of Mitsubishi Electric, which collects data from the sensors and control the actuating mechanisms of the plant. The main components of PLC are base unit, power supply module and the central processing unit module (CPU). Additionally, the controller is equipped with input and output modules of analog and digital signals, as well as with the line of communication modules (Ethernet, Modbus TCP, CC-Link). A special program implementing the connection between the PLC and the upper level is recorded in the PLC [7, 8]. In the upper level, a project of the dedicated SCADA system based on LabVIEW DCS Module and the application for processing and analysis of experimental data have been developed. Since the considered PLC is equipped with a Modbus TCP module and LabVIEW has the linked Modbus libraries it has been decided to connect the controller to the existing Ethernet network available at the faculty department and to share data with LabVIEW environment using the protocol Modbus.

\section{Discussion}

Let 's consider the development process of the block diagram in LabVIEW, which will implement the functions of collecting and processing the data. The block diagram consists of several parallel cycles. Each cycle performs certain functions.

Figure 2 shows two cycles in the block diagram of the program LabVIEW used for reading data from Modbus registers and OPC / DDE-server and for displaying the data on the front panel.

On the left the first cycle is designed to read the parameters from the sensors. The functional blocks Read Holding Register to read Modbus registers (liquid level in the tanks, pressure, temperature) from the library previously connected to the LabVIEW are included in this cycle [9]. To access the Modbus registers first it is necessary to make a TCP connection specifying IP-address and port of the PLC. In this cycle the obtained values are put in an array and in order to filter noise the average values are taken from 5 points. To output the data in the SI units on the front panel the transformation operations are performed and data are put into local variables. Also in this cycle the flow rate values are read from the OPC / DDE server of IM-2300 heat and energy controllers by means of operation functions with the DDE mechanism.

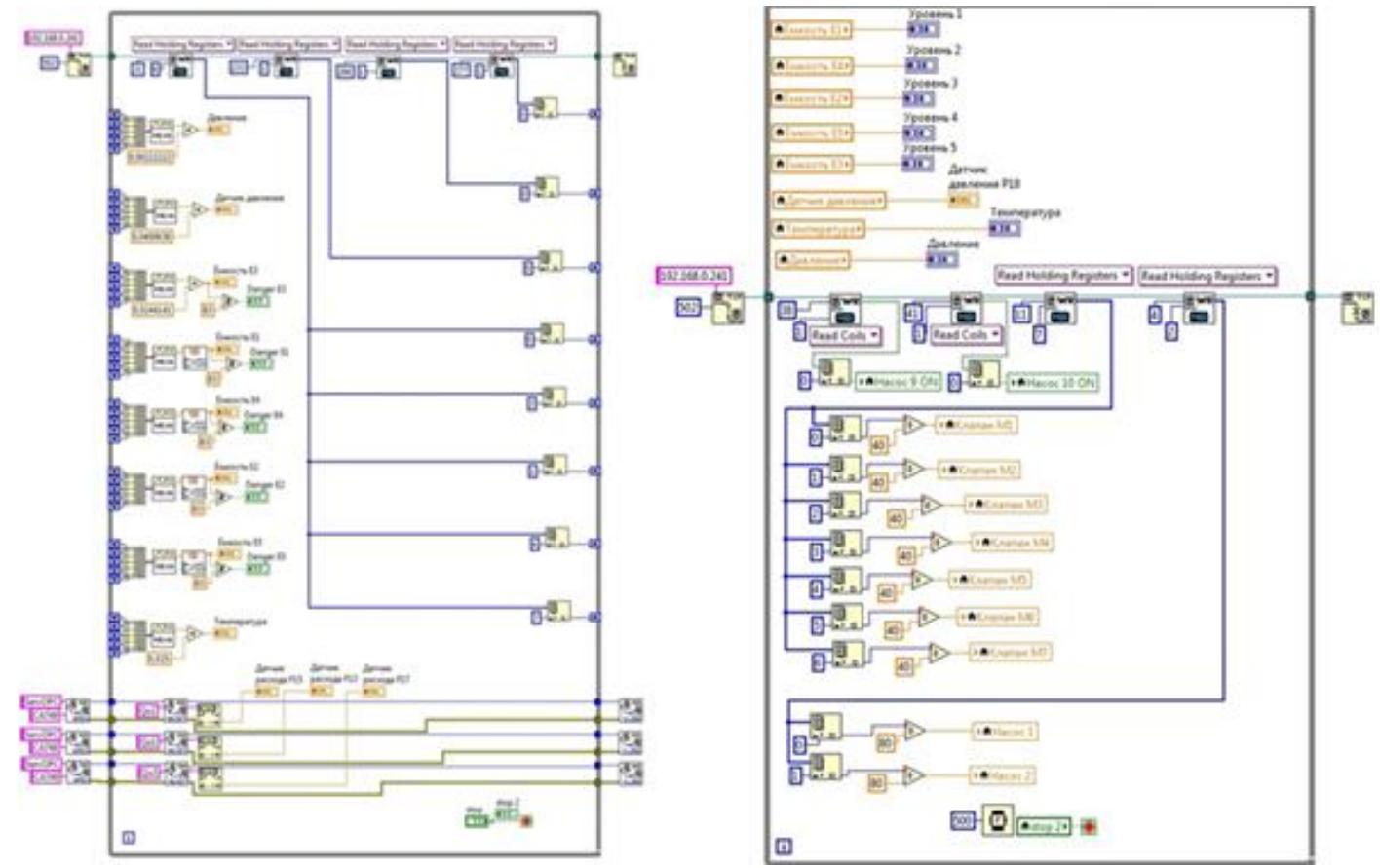

Fig. 2. Block diagram of data reading and visualization

The second cycle shown in Figure 2 on the right, is designed to display the data on the front panel, as well as to read the state of the actuating mechanisms (pumps and valves) and includes a time delay in $500 \mathrm{~ms}$. Similar to the above cycle the functional blocks Read Holding Register to read the valve positions and pumps rotation frequency as well as the blocks Read Coil to read 
boolean state variables for pumps are located here. For data visualization the local variables created in the first cycle are read, and they are written in the appropriate indicators on the front panel.

Figures 3 and 4 show the block diagrams of cycle control and event handling of the experimental plant. In this cycle a special structure of LabVIEW Event Structure to handle the events is placed. The above figures show the same cycle, but they present two different events on changing the element state or value on the front panel. For the example Figure 3 indicates a block diagram for handling the event of pressing the button to turn on / off the pump. The functional unit Write Single Coil to write a pump state bit into the register Modbus is placed here. Figure 4 shows the block diagram of event handling to change the task for opening / closing a valve. With the help of the functional block Write Single Register and simple conversion of entered values into controller units the set valve state is written into the register Modbus. Similarly to reading cycles and data visualization for communication with PLC the TCP connection is made and closed after the cycle implementation.

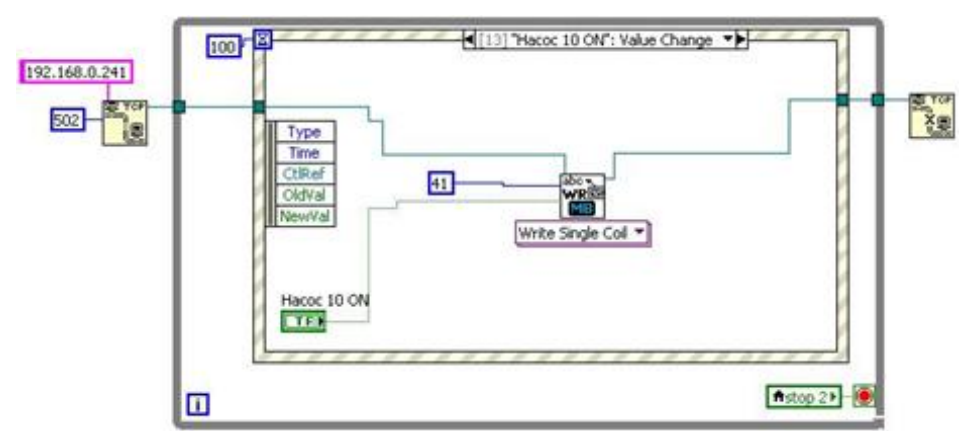

Fig. 3. Block diagram of event handling as an example of the pump switching

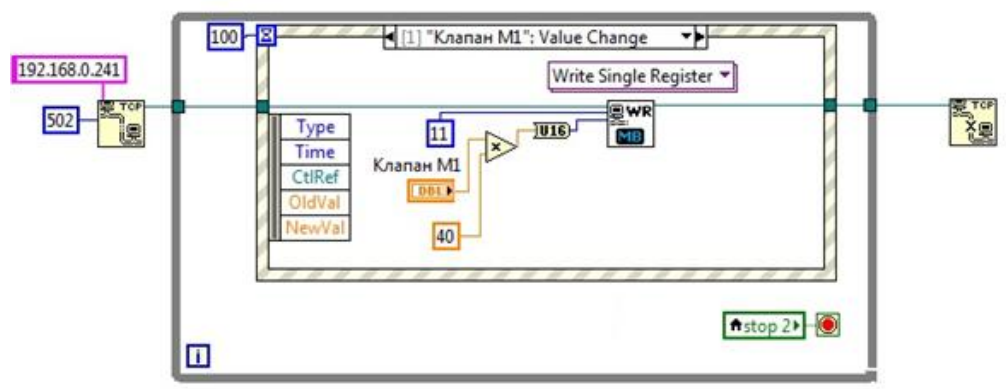

Fig. 4. Block diagram of event handling as an example of the valve position

Figure 5 shows the block diagram implementing the construction of a transition process graph of changing the level for the selected tank. Data for the graph construction are obtained from a reading cycle presented in Figure 2. By plotting the graph the specific period of placing the measured values on a graph using the temporary delay in the cycle can be set. The cycle has several selection structures (Case Structure) allowing the users to start or stop the procedure of graph construction, as well as to select the tank to display on the graph. Simultaneously with the graph construction in the cycle the data are recorded in the * xls file format. 


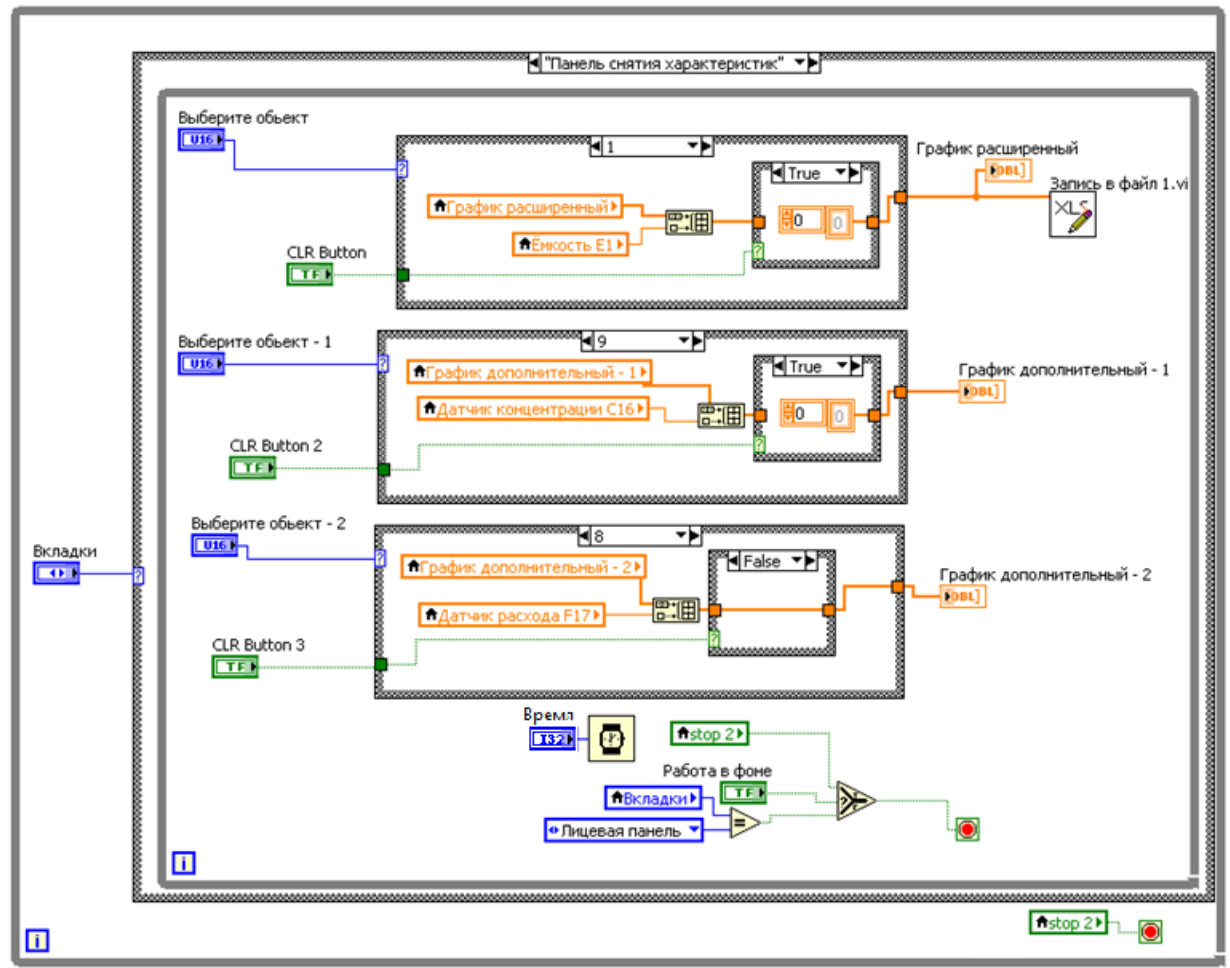

Fig. 5. Block diagram of graph construction and saving the data in a file

As result of our development the front panel of the software environment is produced in the form of a mnemonic diagram of the technological plant process and contains the elements required to control the actuating mechanisms as well as and the visualization of various technological parameters [10]. As shown in Figure 6 the user interface of the software complex is implemented in LabVIEW environment using the DSC module components.

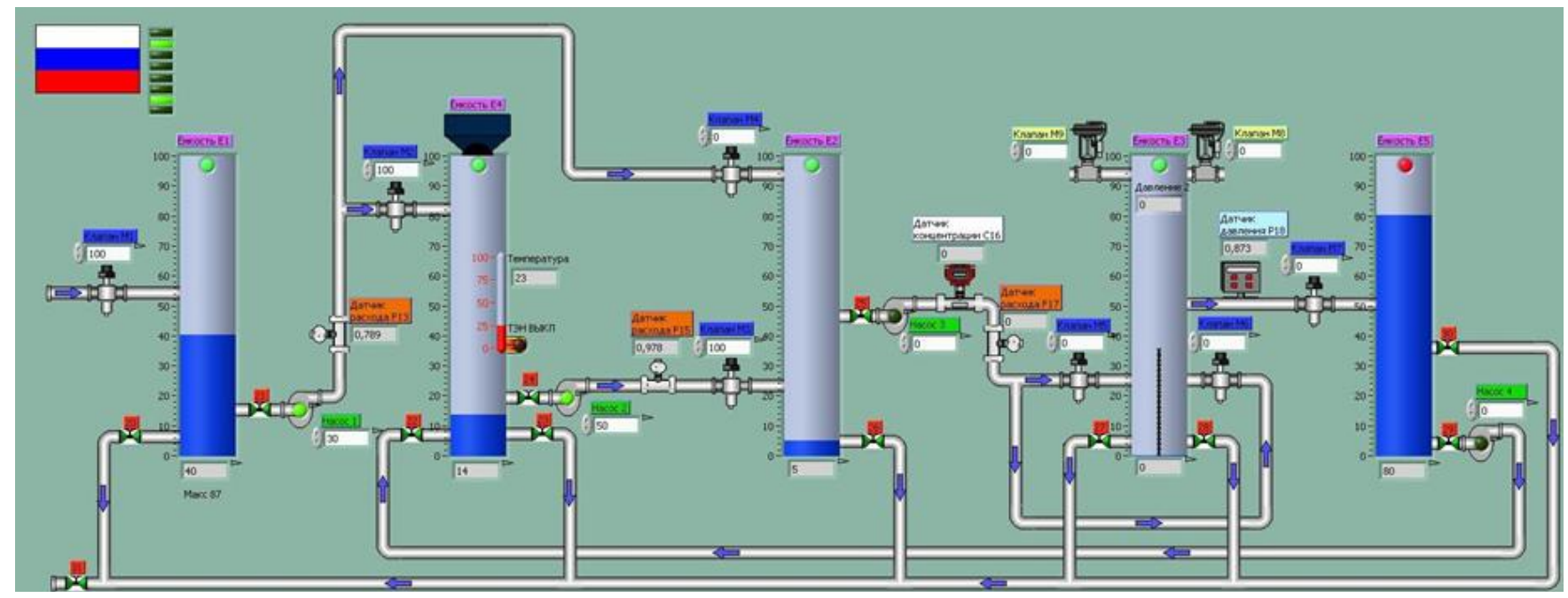

Fig. 6. Front Panel of software complex for the experimental plant

On the front panel there are technological plant tanks connected by a piping system, pumps, adjustable valves and values displayed from all the sensors. The user interface of the software complex is clear and simple to operate. The users select the investigated section of the technological process and set the parameters (the level, flow rate, pressure, etc.). For example, one of the local automation tasks is to maintain a given level of the mass in various technological tanks. For the synthesis and calculation of the level controller it is necessary to perform the procedure of 
control object identification and to read static and transient response from the object. Let 's consider the graph reading procedure of filling the first tank. To conduct the experiment it is necessary to set the control action to open the valve. Further reading the selected characteristics is taken place at the same time during the testing process users can simulate the disturbing action, switching on the pump, evacuating mass from the tank.

As an example, Figure 7 shows the graph of the transient response of the level variation received as a result of filling the E1 tank with water up to $80 \%$. According to this characteristic one can evaluate the nature of the transition process and use the information obtained in the process of the synthesis and calculation of the controller level.

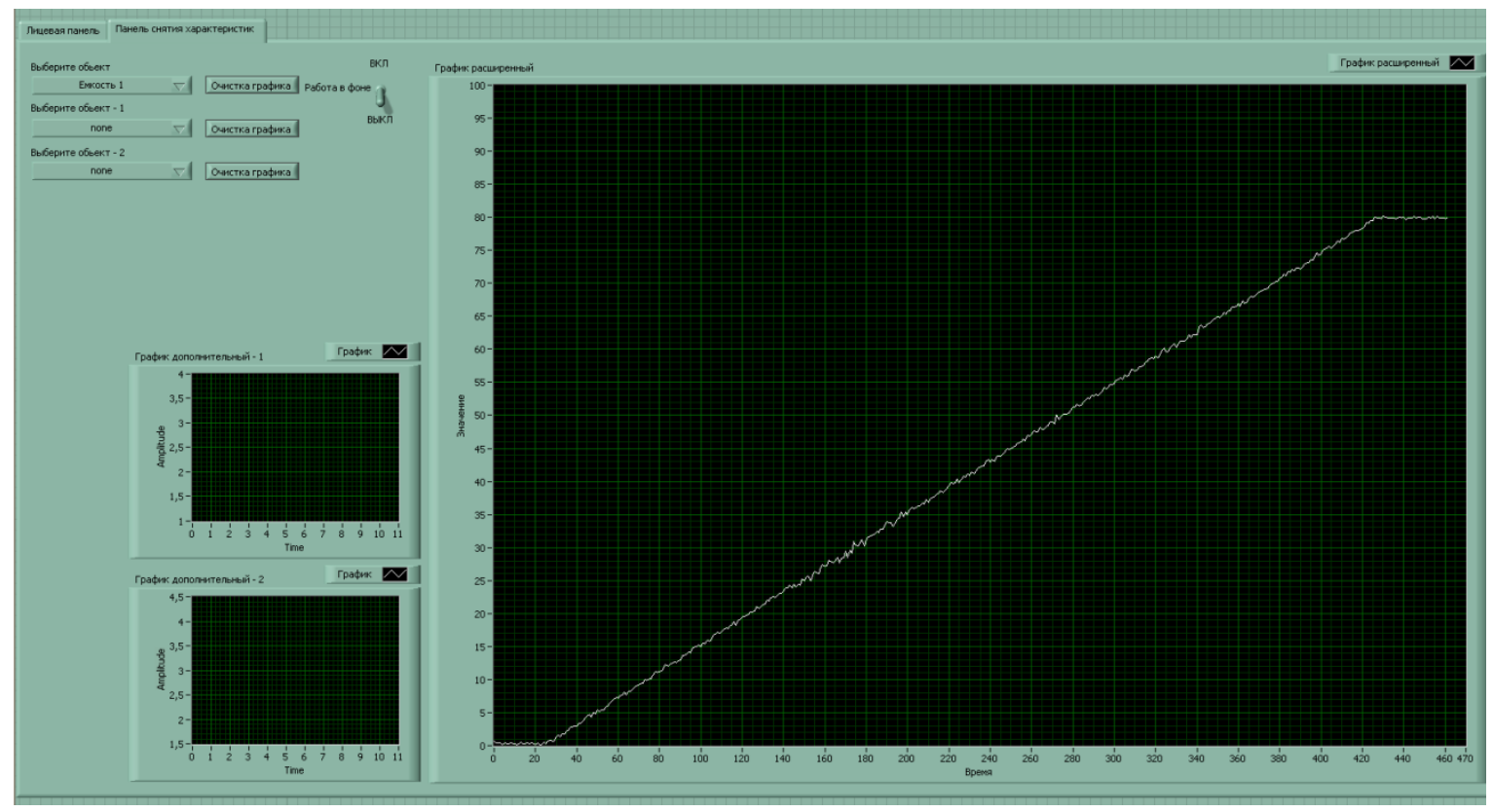

Fig. 7. Graph of the transition process of tank filling

It should be stressed that software and hardware complex considered in the paper is an integral part of the intelligent automated control system of the physical model for the pulp and paper industry.

Implementation of the software and hardware complex for the experimental plant will allow the researches to carry out a number of experiments on technological process investigation as well as setting and optimization of the control system.

The problem solution of the criteria-based comparison according to the similarity theory of hydrodynamic processes will enable one to focus the experimental data on the real technological process for pulp and paper production [11].

The possibilities for analysis and adjustment of CAM projects proposed by the complex design allow us to develop software in the laboratory environment and to reduce project costs and implementation period.

In addition, this complex can be presented also as a virtual simulator to master the desired abilities, knowledge and skills of the students and engineering staff. Created in the LabVIEW environment the project is a training tool for laboratory work with students. It is rather easy to understand and it includes all the basic elements of control and visualization of the technological processes in order to display information, graphics, animation, linked to real data obtained from sensors.

In conclusion it should be mentioned that the next step in the program development is module working out for the synthesis and setting the individual local control loops of the technological parameters for the experimental plant.

\section{References:}

1. Ivanov S.N. Paper theory. Moscow: Paper school, 2006. pp. 696. 
2. Kolomytsev V.G., Dadenkov D.A., Ponosova L.V., Chestikov A.P. Identification laboratory water system parameters for construct of disconnected control system // Bulletin of Perm National Research Polytechnic University. Electrical engineering, information technology, control systems. 2009. no. 3. pp. 200-208.

3. Dadenkov D.A., Ponosova L.V., Petrochenkov A.B., Druzyakin I.G., Leysle A.G..The development of the experimental plant of simulation of control loops process of paper production company OOO "Perm carton" // Energy. Innovative directions in energy. CALS-technologies in the energy sector. 2010. pp. 196-206.

4. J. Travis. LabVIEW for all. Moscow: MQM Press; PriborKomplekt, 2005. pp. 544.

5. Klimentiev E.K. Basis of graphical programming in LabVIEW environment. Study guide. Samara: Samara state aerospace university, 2002. pp. 65.

6. Dadenkov D.A., Petrochenkov A.B. Experience creating laboratory-training complex for training specialists in the field of automated technological process control systems // "Nauchnotekhnicheskie vedomosti SPbGPU” (St. Petersburg State Polytechnical University Journal). 2009. no. 5 (87). pp. 251-255.

7. Iarmonova O., Petrochenkov A., Krause B. Development of Gas Turbine Fast Mathematical Model Simulation Module for Software Complex «Electrodin» based on LabVIEW / European Researcher, 2013, Vol.(61), № 10-2, P. 2488-2501. DOI: 10.13187/issn.2219-8229

8. Dadenkov D.A., Cheremnyh D.N., Kaverin A.A. Development and realize of control technological process algorithm of experimental plant of control loops imitation of pulp and paper production // Energy. Innovative directions in energy. CALS-technologies in the energy sector. 2012. no. 1. pp. 296-308.

9. Vinogradova N.A., Listratov Ja.I., Sviridov E.V. Development of application-dependent software in LabVIEW environment: study guide. Moscow.: MJeI, 2005. pp. 48.

10. Chestikov A.P., Dadenkov D.A., Petrochenkov A.B., Creating graphical interface of control system of training and research stand simulating the process of preparing and filing of paper pulp // Bulletin of Perm National Research Polytechnic University. Electrical engineering, information technology, control systems. 2010. no. 4. pp. 124-128.

11. Dadenkov D.A., Ponosova L.V., Druz'jakin I.G., Petrochenkov A.B. Solving methods analysis of similarity technological processes task of paper production in experimental and plant environments // Scientific research and innovation. 2012. no. 1-4. pp. 175-184. 